\title{
Pais de Primeira Viagem: A Experiência da Paternidade na Meia-Idade
}

\author{
Mayara Colleti \\ Fabio Scorsolini-Comin \\ Universidade Federal do Triângulo Mineiro \\ Uberaba, $M G$, Brasil
}

\begin{abstract}
RESUMO
O objetivo deste estudo foi compreender os processos desenvolvimentais de homens que se tornaram pais pela primeira vez após os 40 anos. Foram entrevistados quatro pais, com idades entre 44 e 58 anos, a partir da técnica da história de vida e de um roteiro semiestruturado. A análise de conteúdo revelou que a assunção da paternidade está intimamente relacionada à percepção do próprio genitor. Destacaram-se nos discursos aspectos positivos e negativos da paternidade nessa fase e também a importância de conciliar as funções parentais com a conjugalidade e as relações familiares e sociais. A paternidade na meia-idade é um fenômeno que nos obriga a analisar diferentes facetas do desenvolvimento, tanto físicas como culturais, reconhecendo a necessidade de novas investigações com essa população.
\end{abstract}

Palavras-chave: Paternidade; Parentalidade; Meia-Idade; Masculinidade; Desenvolvimento.

\section{ABSTRACT}

\section{First-Time Parents: The Parenthood Experience in Midlife}

This study aims to understand the developmental processes of men who have become fathers for the first time after age 40. Four fathers, between 44 and 58 years old, were interviewed through a life story approach and a semi-structured guide. Content analysis demonstrates that parenthood acknowledgement is closely related to parent's own perception about parenthood. Fathers' discourses highlight positive and negative aspects of parenthood on this life stage and also the importance to conciliate parental functions, conjugality and familiar and social relations. Parenthood in midlife is a phenomenon that compels us to analyse the different physical and cultural aspects of development, leading to the acknowledgement of the necessity of new research concerning this population.

Keywords: Parenthood; Parenting; Midlife; Masculinity; Development.

\section{RESUMEN}

\section{Padres por Primera Vez: La Experiencia de la Paternidad en la Mediana Edad}

El objetivo de este estudio fue comprender los procesos de desarrollo de los hombres que se tornaron padres por primera vez después de los 40 años. Fueron entrevistados cuatro padres, entre 44 y 58 años de edad, por medio de la historia de vida y de un guion semiestructurado. El análisis del contenido revelo que la aceptación de la paternidad está íntimamente relacionada a la percepción del proprio genitor. Se destacan en los discursos aspectos positivos y negativos de la paternidad en esta etapa y también la importancia de unir las funciones paternas con la conyugal y las relaciones familiares y sociales. La paternidad en la media-edad es un fenómeno que nos obliga a analizar diferentes etapas de desarrollo, tanto físicas como culturales, reconociendo la necesidad de nuevas investigaciones con esa población.

Palabras clave: Paternidad; Media-Edad; Masculinidad; Desarrollo. 
$\mathrm{Na}$ literatura científica, as pesquisas sobre a maternidade e a díade mãe-filho sempre ganharam maior destaque, sendo escassos os estudos dedicados à figura paterna e as experiências do pai no contexto familiar (Costa \& Rossetti-Ferreira, 2009a, 2009b). Foi apenas a partir do início dos anos 1970 que se verificou uma investigação mais intensa acerca da temática (Lamb, 2000), em que as transformações sociais nos espaços público e privados, sobretudo a partir da década de 1960, são apontadas como marcos de importantes mudanças socioculturais no que se refere às concepções de masculinidade e feminilidade (Freitas et al., 2009).

Neste panorama, a entrada maciça das mulheres no mercado de trabalho e as lutas feministas demandaram maior proximidade masculina em relação ao espaço doméstico, solicitando uma posição mais ativa do homem no cotidiano da família e também no cuidado dos filhos (Hennigen, 2010). É no bojo desses estudos e reflexões que a paternidade desponta como um elemento importante, havendo a assunção de "um novo pai" (Balancho, 2004; Vieira \& Souza, 2010). Antes considerado somente o provedor do sustento do filho, começa a ser chamado, na contemporaneidade, para exercer mais ativamente suas funções. Com isso, o modelo de família tradicional, no qual o pai é o nível mais alto de hierarquia, dá lugar a um pai mais íntimo, sensível, participativo e envolvido na criação dos filhos, que apresenta como diferencial o envolvimento afetivo (Gomes \& Resende 2004; Vieira \& Souza, 2010). Com isso, as relações de autoridade vão dando espaço, de forma gradativa, às relações permeadas por afeto e negociações, possibilitando que pais e mães compartilhem os cuidados e estreitem os vínculos afetivos com os filhos, de forma que a paternidade contribui para a ruptura de estereótipos de uma masculinidade insensível e intocável (Freitas et al., 2009).

Atualmente a paternidade tem recebido contribuições de estudos advindos de diversas áreas e abordagens teóricas. Contudo, apesar da literatura apresentar evidências consistentes de aumentos nos níveis de envolvimento do homem no interior da família, não é possível generalizar essas considerações (Balancho, 2004), sendo fundamental que as práticas paternas em cada sociedade sejam vistas dentro de um contexto específico (D. W. Shwalb \& B. J. Shwalb, 2014). No entanto, apesar da concepção de paternidade sofrer modificações ao longo do tempo e variar de acordo com os contextos, a gestação e o nascimento dos filhos constituem não só para a mulher, mas também para o homem, fases de mudanças, com transformações e incertezas que acompanham a aquisição de novos papéis e responsabilidades antes inexistentes (Freitas,
Coelho, \& Silva, 2007), apontando, assim, para a necessidade de investigar os diferentes atores envolvidos na transição para a parentalidade (Cecílio \& ScorsoliniComin, 2013; Rossetti-Ferreira \& Costa, 2012).

A maioria dos estudos sobre a experiência da paternidade concentra-se na fase da adolescência (Levandowski, 2001; Orlandi \& Toneli, 2005; Trindade \& Menandro, 2002), com raras referências a homens na meia-idade (Trindade \& Bruns, 2004, 2007). Esse fenômeno pode ser também um reflexo da recente consideração da meia-idade como fase do ciclo vital, abarcando especificidades desenvolvimentais, como a revisão acerca de objetivos e metas para o futuro.

Na Psicologia do Desenvolvimento, a meia-idade é concebida por Erikson (1976) como um momento em que o ser humano procura o sentido de sua contribuição no mundo em sua família e no trabalho, podendo disparar diversas crises neste estágio, como sentimentos relacionados à transmissão de conhecimentos, valores e compreensões de mundo para seus descendentes, ou mesmo de ter atingido seus objetivos profissionais previamente delineados. Ressalta-se que não há consenso na literatura científica em relação à definição da faixa etária que corresponde à meia-idade (Ferreira, 2008). Alguns autores consideram que a mesma abrange a fase que vai dos 40 aos 60 anos de idade (Leão \& Gíglio, 2002). Outros argumentam que o aumento da expectativa de vida e a redução do número de filhos por família fizeram essa fase se tornar a mais longa do ciclo de vida familiar, costumando decorrer entre os 45 e os 65 anos (Ribeiro, 2005). Há, ainda, quem a defina apenas como a faixa etária dos 50 anos (Ferreira, 2008). Neste estudo, compreendemos que a meia-idade recupera diversas experiências que nem sempre podem ser delimitadas cronologicamente de modo preciso. Visando a ampliar o conceito, a exemplo do estudo de Leão e Gíglio (2002), a meia-idade é considerada no presente estudo como fase que vai dos 40 aos 60 anos de idade.

A partir do exposto, o objetivo deste estudo foi compreender os processos de desenvolvimento de homens que se tornaram pais pela primeira vez após os 40 anos de idade. Buscou-se, a partir do relato desses pais, investigar os sentidos que os mesmos produzem sobre a paternidade e compreender ainda as principais características dessa vivência em tal período da vida.

\section{MÉTODO}

\section{Tipo de estudo}

Trata-se de um estudo exploratório e transversal, fundamentado na abordagem de pesquisa qualitativa. $\mathrm{O}$ projeto que deu origem a este estudo foi aprovado 
pelo Comitê de Ética em Pesquisa da universidade de origem dos autores.

\section{Participantes}

Participaram deste estudo quatro homens heterossexuais que atendiam aos seguintes critérios: (a) tornaram-se pais pela primeira vez com 40 anos de idade ou mais; (b) casados, recasados ou unidos consensualmente e que residem com suas companheiras; (c) possuem pelo menos um filho (biológico ou adotado); (d) residem em cidades do interior do estado de Minas Gerais e São Paulo. Não houve restrições em relação ao número de filhos, grau de escolaridade e classificação socioeconômica. A amostra foi composta por critério de conveniência. A caracterização dos participantes será apresentada no item Resultados e Discussão.

\section{Instrumentos}

Foram utilizados os seguintes instrumentos para a coleta de dados: (a) Técnica da História de Vida do participante, que consistiu em pedir ao respondente que descrevesse, com as suas próprias palavras e do modo como desejasse, a sua história de vida até o momento. Trata-se de uma técnica livre que visa investigar de que modo a pessoa constrói explicações e descrições para a própria trajetória (Meihy \& Holanda, 2010). A solicitação foi para que o participante contasse sobre a sua história de vida até o momento, não delimitando eventos ou fases. Por essa técnica, apresentou-se a seguinte sentença disparadora: "conte-me com as suas palavras e do modo como preferir a sua história de vida até o momento". Assim, a menção à paternidade poderia ou não ocorrer no marco da história de vida; e (b) Entrevista semiestruturada com o participante, que consistiu em um roteiro de entrevista semiestruturado, elaborado pelos próprios pesquisadores, com perguntas sobre escolaridade, renda familiar, emprego/ ocupação, religião, quantidade de filhos, experiência da paternidade, experiência da conjugalidade a partir da parentalidade, dificuldades e possibilidades no processo de construção da paternidade e demais questões que atendiam aos objetivos do presente estudo. A construção do roteiro foi orientada pelos estudos disponíveis na literatura sobre paternidade na contemporaneidade e pelos objetivos específicos do estudo. O objetivo do roteiro foi complementar as informações porventura trazidas na história de vida, permitindo uma exploração mais aprofundada do objetivo do estudo.

\section{Procedimento}

Coleta de dados. Os participantes foram recrutados a partir de contatos sociais dos pesquisadores, por meio do procedimento bola de neve, em que um participante faz indicações de outros possíveis colaboradores, que se enquadrem nos critérios de inclusão. Após contato prévio com os participantes e a assinatura do Termo de Consentimento Livre e Esclarecido, os dados foram coletados em horários e locais escolhidos pelos participantes, dentre os quais residências e locais de trabalho, onde se buscou encontrar um espaço reservado que assegurasse a privacidade do participante, bem como seu conforto material e psicológico. Os dois instrumentos foram aplicados em cada um dos participantes, individualmente, em um único encontro. Primeiramente utilizou-se a técnica da história de vida e, posteriormente, a entrevista semiestruturada. As entrevistas foram audiogravadas mediante o consentimento do participante e transcritas na íntegra e literalmente para posterior análise. Os participantes receberam nomes fictícios.

Análise de dados. Após a transcrição das entrevistas, as mesmas foram analisadas em profundidade, destacando-se, em um primeiro momento, os eixos temáticos encontrados a partir das falas de cada um dos participantes, ou seja, realizou-se uma análise vertical do material. Em um segundo momento, foi realizada uma análise horizontal de todas as entrevistas, elencando os pontos de semelhança e as diferenças entre essas, também a partir dos eixos temáticos construídos. Para a realização e organização dessas análises, foram utilizados os procedimentos de análise de conteúdo temático, a partir de análises verticais (caso a caso) e horizontais (integradoras de todos os casos), que envolveram leitura flutuante, seleção de unidades de significados, categorização e interpretação. Neste estudo, foi explorada a análise horizontal das entrevistas, a partir dos pontos de encontro e de discordância entre os entrevistados. Os dados foram apresentados em três eixos temáticos principais, construídos a partir da análise de conteúdo de todas as entrevistas (corpus): (a) A construção do modo de ser pai; (b) Aspectos positivos e negativos da paternidade na meia-idade; (c) Repercussões da paternidade na conjugalidade e nas relações sociais e familiares.

Em termos de marco teórico da presente investigação, há que se destacar que a literatura sobre parentalidade ainda se concentra na psicanálise (Staudt \& Wagner, 2008), existindo estudos no campo da Psicologia do Desenvolvimento que consideram fundamentalmente os elementos ao longo do ciclo vital, seus processos, mudanças e permanências (RossettiFerreira \& Costa, 2012), bem como as crises promotoras de desenvolvimento (Erikson, 1976). Como forma de possibilitar o diálogo entre os estudos contemporâneos da paternidade, que já partem do pressuposto de que o 
ser pai tem sido marcado por profundas transformações, a presente investigação buscou fomentar essa discussão sem recorrer exclusivamente a uma dada abordagem, abarcando, portanto, estudos disponíveis na literatura científica sobre paternidade (Gabriel \& Dias, 2011; Gomes \& Resende, 2004; Levandowski \& Piccinini, 2006).

\section{RESULTADOS E DISCUSSÃO}

Em relação à caracterização da amostra, participaram do estudo quatro homens heterossexuais, com idades entre 44 e 58 anos. A Tabela 1 apresenta a caracterização completa da amostra.

No que se refere às explicações para a paternidade na meia-idade, pode-se observar que os quatro participantes tornaram-se pais após o casamento ou união estável, não tendo filho em relações anteriores. Adriano e Marcelo casaram-se com 37 anos e 36 anos, respectivamente, e suas esposas tiveram dificuldade para engravidar, enquanto Joel casou-se com 47 anos e Antônio uniu-se com sua companheira com 41 anos, ou seja, quando já estavam na fase do ciclo vital correspondente à meia-idade.

\section{A construção do modo de ser pai}

Este eixo abarca as falas dos participantes que remetem aos aspectos que contribuem na construção da forma que eles exercem a paternidade e se relacionam com seus filhos. Observou-se que o modo como eles compreendem e assumem a paternidade está intimamente relacionado com a percepção que possuem da relação vivida no passado com o próprio genitor. Adriano e Joel revelaram em seus discursos o desejo de, na criação de seus filhos, corrigir o que consideram erros cometidos pelos próprios pais, ao passo que também demonstraram desejar repetir aspectos considerados positivos dessa relação:

TABELA 1

Caracterização dos participantes $(\mathrm{N}=4)$.

\begin{tabular}{|c|c|c|c|c|c|c|c|c|}
\hline $\begin{array}{l}\text { Nome } \\
\text { e Idade }\end{array}$ & Escolaridade & Profissão & Estado Civil & Religião & $\begin{array}{l}N^{o} \text { de } \\
\text { filhos }\end{array}$ & $\begin{array}{c}\text { Idade } \\
\text { dos filhos }\end{array}$ & $\begin{array}{l}\text { Renda mensal } \\
\text { em reais }\end{array}$ & $\begin{array}{c}\text { Explicações para } \\
\text { a paternidade na } \\
\text { meia-idade }\end{array}$ \\
\hline $\begin{array}{l}\text { Adriano } \\
44\end{array}$ & $\begin{array}{l}\text { Ensino Médio } \\
\text { Completo }\end{array}$ & $\begin{array}{l}\text { Funcionário } \\
\text { Público }\end{array}$ & Casado & $\begin{array}{l}\text { Católico } \\
\text { Praticante }\end{array}$ & 1 & $\begin{array}{l}\text { Um ano e } \\
\text { setes meses }\end{array}$ & 4.500 & $\begin{array}{l}\text { Casou-se com } \\
37 \text { anos. } \\
\text { Desejava ter } \\
\text { filho logo após o } \\
\text { casamento, mas } \\
\text { a esposa teve } \\
\text { dificuldade para } \\
\text { engravidar. }\end{array}$ \\
\hline $\begin{array}{l}\text { Marcelo } \\
48\end{array}$ & $\begin{array}{l}\text { Formação } \\
\text { Técnica }\end{array}$ & $\begin{array}{l}\text { Funcionário } \\
\text { Público }\end{array}$ & Casado & $\begin{array}{l}\text { Católico } \\
\text { não praticante }\end{array}$ & 1 & Cinco anos & 3.000 & $\begin{array}{l}\text { Casou-se com } \\
36 \text { anos. } \\
\text { Desejava ter } \\
\text { filho logo após o } \\
\text { casamento, mas } \\
\text { a esposa teve } \\
\text { dificuldade para } \\
\text { engravidar. }\end{array}$ \\
\hline $\begin{array}{l}\text { Joel } \\
57\end{array}$ & $\begin{array}{l}\text { Ensino Superior } \\
\text { Completo }\end{array}$ & $\begin{array}{l}\text { Engenheiro } \\
\text { Civil }\end{array}$ & Casado & $\begin{array}{l}\text { Católico } \\
\text { não praticante }\end{array}$ & 3 & $\begin{array}{l}\text { Nove anos; } \\
\text { Seis anos; } \\
\text { Um ano }\end{array}$ & 6.000 & $\begin{array}{l}\text { Casou-se com } \\
47 \text { anos. } \\
\text { Antes de se casar } \\
\text { teve diversos } \\
\text { relacionamentos, } \\
\text { dos quais não } \\
\text { teve filhos. }\end{array}$ \\
\hline $\begin{array}{l}\text { Antônio } \\
58\end{array}$ & $\begin{array}{l}\text { Ensino Médio } \\
\text { Completo }\end{array}$ & $\begin{array}{l}\text { Motorista de } \\
\text { ônibus }\end{array}$ & União Estável & Evangélico & 1 & 13 anos & 2.500 & $\begin{array}{l}\text { Casou-se com } \\
41 \text { anos. } \\
\text { Antes do } \\
\text { casamento } \\
\text { teve diversos } \\
\text { relacionamentos, } \\
\text { dos quais não } \\
\text { teve filhos. }\end{array}$ \\
\hline
\end{tabular}


"Eu sentia que com meu pai, assim, parece que ele sentia vergonha de dá carinho pros filhos. Eu num tenho vergonha não, porque fez falta, então vou sempre dá carinho pra ele, mais vou ensinar muita coisa, ser honesto, trabalhador, incentivar a estuda, assim como meu pai ensinou, mas ainda mais, vou dá o carinho que faltou pra mim." (Adriano, 44 anos)

"Acho que hoje o meu relacionamento com meus filhos é muito maior que o do meu pai comigo, a gente vive mais junto, faz mais coisa junto, né, tem coisa que eu faço que meu pai nunca fez, por isso faço. Ele não dava carinho e eu procuro dar, mas também procuro fazer coisas que ele fazia, ensina o que é certo e errado..." (Joel, 57 anos)

Marcelo e Antônio, por sua vez, revelaram a tentativa de serem pais diferentes, exercendo a paternidade de modo totalmente distinto de seus pais, buscando, dessa forma, romper com modelo recebido de seu genitor. Esse aspecto pode ser notado nas falas a seguir:

"Eu e meu pai não temos nada a ver... Eu sou apegado com meu filho, faço tudo pra ele. Meu pai não, ele era muito quieto, não fazia nada com a gente, só chamava atenção né... Ah eu sou diferente, num quero que ele fique como eu, sinta falta do que o pai não fez." (Marcelo, 48 anos)

"Acho que todo homem quer ser pai sim, mas eu tinha medo de não ser um bom pai, ser um pai ruim igual o meu. Acho que ele pensava que filho era pra trabalhar e ajudar, e não alguém que precisa se educado, mas também amado. Lembro de como meu pai era nossa, quero e sou totalmente diferente..." (Antônio, 58 anos)

O modo como o homem constrói a paternidade e o importante papel que o modelo do próprio genitor ocupa nessa construção têm sido discutidos em diversos estudos que abordam a temática da paternidade. De acordo com Gomes e Resende (2004), a experiência da paternidade pode ser vivenciada tanto como um momento marcado por novos sentidos, transformações e responsabilidades na vida do homem, quanto uma oportunidade para este reviver e reavaliar o relacionamento vivenciado com seu próprio pai, uma vez que, assim como ressaltam Gabriel e Dias (2011), a experiência vivida com o próprio pai é a referência mais próxima que o homem tem de como o papel paterno pode ser desempenhado.
Para Gabriel e Dias (2011), ao se tornar pai o homem avalia o modelo recebido do próprio genitor, podendo repeti-lo no todo ou apenas em alguns aspectos, ou ainda, romper totalmente com o mesmo. Pode-se perceber que Adriano e Joel, ao relatarem o modo como percebiam o relacionamento tido com os seus pais, citaram alguns aspectos que procuravam repetir na relação com seus filhos, como o ensinamento de valores, ao mesmo tempo em que identificaram questões que desejavam fazer diferente nessa relação, como a proximidade afetiva. Dessa forma, aspectos avaliados pelos participantes como negativos são refutados, surgindo, assim, não só a vontade de reparação dos mesmos na relação com seus filhos, mas também o desejo de repetir os aspectos positivos da relação (Gabriel \& Dias, 2011; Gonçalves, Guimarães, Silva, Lopes, \& Piccinini, 2013; Levandowski \& Piccinini, 2006).

Já nos relatos de Marcelo e Antônio foi possível perceber o desejo de exercer a paternidade e relacionar-se com os filhos de modo totalmente distinto do modelo de paternagem experienciado, assim como encontrado no estudo de Gomes e Resende (2004), em que o relacionamento distante e frio com seus pais os fez desejar ser um pai diferente. Embora esse momento de recordar e reviver o relacionamento tido com o próprio genitor os fizesse entrar em conflito com seus sentimentos, teve, também, uma finalidade de estimulá-los a recriar e afastar do modelo que os acompanhou a vida toda, permitindo-se ter uma vivência mais íntima com os filhos (Gomes \& Resende, 2004).

Observou-se ainda, nos relatos de Adriano e Joel, em que ambos percebiam acertos e falhas no modelo de paternidade exercido pelo próprio pai que, da mesma forma que os participantes do estudo de Gabriel e Dias (2011), relataram essas falhas com muito desconforto, enfatizando que não consideravam os pais pessoas más, buscando elementos que suavizassem essa fala, como por exemplo, "no relacionamento com os pais antigamente, todos os pais antigamente eram mais frios né..." (Joel, 57 anos). Ressalta-se que não desconsideramos que esta seja uma percepção real das transformações que o papel do pai vem sofrendo nas últimas décadas. No entanto, percebeu-se que se tratava também de uma busca de minimizar a culpa que sentiam ao falar mal dos próprios pais. Para Gabriel e Dias (2011), essa culpa talvez advenha do fato de que esses pais se tornarão avós no futuro e passarão pelo mesmo movimento, ou seja, de seus filhos aceitarem alguns aspectos e repudiar os que não servem. Além do mais, revogar completamente as experiências com o próprio pai é algo que pode ser muito doloroso. 
Observa-se que, ao se constituir como pai, o homem (re)avalia a relação vivida com o próprio genitor, mas não deixa de questionar essas concepções dadas a priori, tomando para si tanto o modelo de paternagem recebido, como o modelo de como um bom pai deve ser, de acordo com o seu próprio imaginário. Ao tomar essa atitude, o homem concebe uma nova e singular maneira de ser pai, baseando-se no que está vivenciando no momento (Gabriel \& Dias, 2011). A esse respeito, a perspectiva da psicanálise dos vínculos sociais de Benghozi (2010) compreende que os vínculos entre pais e filhos no início da vida podem ser remalhados ou desmalhados em função dos vínculos estabelecidos na vida adulta. Desse modo, as experiências na vida adulta, os relacionamentos interpessoais e até mesmo a conjugalidade podem ser elementos para a reconfiguração de vínculos iniciais possivelmente assimilados com sofrimento psíquico ou com "falhas" e "rasgos" na infância, ou seja, de modo insatisfatório.

Outro aspecto a ser destacado é que no discurso dos quatro participantes o desejo de uma proximidade afetiva com os filhos se fez presente, tanto nos casos em que os participantes consideraram essa questão como uma falha do pai, quanto nos casos em que os pais eram vistos como extremamente frios e distantes. A esse respeito, Vieira e Souza (2010) destacam, além da tentativa de reparação do modelo do próprio genitor, as mudanças sociais ocorridas nas últimas décadas, em que se considera que o modelo tradicional de paternidade, marcado pelo distanciamento afetivo dos filhos e caracterizado pelo sustento financeiro da família, começa a ser substituído por um "novo pai" presente na contemporaneidade, com maior aproximação afetiva com os filhos e envolvido em seus cuidados diários, o que pode ser observado nas seguintes falas:

"Não existe isso do que é meu e o que é dela não. Eu faço de tudo com ele, sabe, brinco, ajudo a cuida, cuido sozinho também. Quando ele tava menorzinho, eu acordava e balançava ele pra dormir, tentando não acordar ela. Isso tanto eu como ela, a gente divide todas tarefas." (Adriano, 44 anos)

"Lá em casa não tem nada específico pra um ou pra outro não, quando um não pode o outro faz. O que eu num sabia ela me ensino e me chama a atenção. Tudo que você pensar hoje eu faço, comida, lavo, passo, arrumo a casa, mamadeira, comida pra ele, banho troco, tudo, tudo." (Marcelo, 48 anos).
"Tanto eu quanto ela, a gente participa de tudo, tanto de escola quando do dia a dia. Ela me incentiva muito (se referindo à esposa). Então não tem uma separação... Tudo a gente faz, tá certo que tem coisa que ela faz mais e tem coisa que eu faço mais, só que tudo de forma natural, não tem nada de um só." (Joel, 57 anos)

Como é possível perceber, assim como apontado por Gomes e Resende (2004), trata-se de pais mais presentes e identificados com as exigências contemporâneas da família, que expõem sua face afetiva de modo oposto à concepção tradicional que exigia distanciamento físico e afetivo. Assim, ao se revelarem enquanto homens dotados de sensibilidade, conciliam na necessidade paterna atual que imprime em suas vidas o desejo de superar a dificuldade que sempre fez parte da infância.

Notadamente, percebe-se que a construção e a vivência da paternidade apresentam muitos desafios, seja porque atualmente vive-se em um momento de repensar seu lugar afetivo na criação dos filhos, seja porque se tornou difícil sustentar a visão de um pai apenas responsável pelo sustento financeiro da família. No entanto, assim como observado nas falas, deve-se ressaltar que tais aspectos envolvem diretamente o lugar ocupado pela mãe na transição e exercício da parentalidade, o qual influencia as questões que envolvem a paternidade, uma vez que o afeto foi historicamente um atributo materno (Cúnico \& Arpini, 2013), enquanto que ao homem foram impostas as responsabilidades sociais de provedor, o que pode lhe trazer prejuízos no campo da subjetividade (Freitas et al., 2007). A masculinidade sempre esteve social e historicamente associada à não demonstração de afeto, sensibilidade e cuidado, o que tem sido repensado especificamente no modo de ser pai observado na contemporaneidade. Ser pai, desse modo, é uma possibilidade de ressignificar o papel social exclusivamente machista e provedor atribuído ao homem (Silva, 2006).

Ainda que os participantes demonstrem assumir um papel mais participativo na vida dos filhos, em que não há uma divisão de tarefas entre eles e suas companheiras, Staudt e Wagner (2008) alertam para o fato de que as crenças e valores presentes no imaginário social não se transformam abruptamente, e que, juntamente com essa demanda de um homem mais presente na vida privada, observamos que ainda persiste no senso comum a vinculação da maternidade a uma aura idealizada. Dessa forma, resgatar a presença do pai no ambiente familiar, permitindo que este se faça presente nas mais diversas atividades, é uma tarefa 
que desafia não apenas os pais, mas também as mães e todos os envolvidos nas questões familiares (Cúnico \& Arpini, 2013).

\section{Aspectos positivos e negativos da paternidade na meia-idade}

No que tange aos sentidos atribuídos à paternidade na meia-idade, os participantes atribuíram aspectos que consideram positivos e negativos dessa vivência. Todos apontaram possuir maior maturidade e responsabilidade, conquistada, segundo eles, com o passar dos anos, sendo relatada como algo característico de sua fase do ciclo vital, o que foi considerado um aspecto positivo do ser pai após os 40 anos:

"Eu acho que até uns 30, 35 anos, principalmente o homem é muito irresponsável, é muito moleque. Eu acho que se pai nessa idade a gente ganha por ser mais responsável, mais consciente do que ta fazendo." (Adriano, 44 anos)

"O jovem já dá valor às mocinhas, as baladas, aquela fervilhação, querem viver intensamente. Então no meu caso já não, eu penso muita mais na família, já saí o que tinha que sair... Eu acho que o depois dos 40 a pessoa já sabe o que quer, ela já tá com a vida mais equilibrada financeiramente." (Joel, 57 anos)

É possível observar que, ao relatarem acerca da experiência da paternidade na meia-idade, os participantes não só partem da compreensão de que o ser humano adquire maturidade e responsabilidade com o passar dos anos, mas também recorrem à comparação com o modo que eles acreditam que pais mais novos exercem a paternidade. Como dito anteriormente, a literatura científica acerca da paternidade relacionada à idade ainda é bastante escassa. A afirmação e percepção dos participantes de que pais mais jovens, principalmente adolescentes, exercem o papel paterno de maneira irresponsável e com menos maturidade também se faz presente na hipótese de alguns estudiosos ao estudar a paternidade na adolescência. Levandowski e Piccinini (2002) ressaltam que os achados na literatura científica em relação aos pais adolescentes nem sempre apontam na mesma direção. Enquanto alguns estudos evidenciam que a interação do pai adolescente com o bebê ficaria prejudicada pelas limitações desenvolvimentais do próprio pai, outros estudos demonstram que os adolescentes são capazes de superar essas adversidades. No entanto, ressaltam que as teorizações apontam mais para a hipótese de menor responsividade do pai adolescente ao bebê.
Estudos realizados por Trindade e Menandro (2002) e Sampaio, Villela e Oliveira (2014) com pais adolescentes corroboram com a percepção dos pais do presente estudo ao revelarem que dentre as mudanças consideradas pelos jovens de maior impacto após a paternidade está à perda de liberdade, traduzida pela diminuição nos contatos sociais e impossibilidade de ir a festas. Sentimentos de inadequação ao papel paterno, por se considerarem imaturos, inexperientes, sem condições de alcançar suas próprias expectativas e exigências em relação ao que é ser um pai, também se fizeram presente nos relatos dos participantes do estudo de Trindade e Menandro (2002). A questão financeira, apontada por Joel, foi considerada uma das principais dificuldades apresentadas pelos participantes do estudo de Sampaio, Villela e Oliveira (2014), em que a maioria dos pais dos adolescentes oferecia apoio financeiro para que os mesmos cuidassem de seus filhos. A esse respeito a literatura acerca da vida adulta intermediária, ou seja, da meia-idade, considera que esta fase seja aquela em que geralmente as pessoas já se encontram profissionalmente estáveis (Kovács, 2010), destacando que a partir da fase adulta e ao longo da vida, as pessoas vão limitando ativamente os seus contatos sociais, aumentando a proximidade emocional e atribuindo maior importância às relações significativas. Essa afirmação é corroborada pelos achados do presente estudo, na medida em que os participantes se percebem como pessoas que ao longo da vida conquistaram certa disponibilidade e desejo de se dedicar à família e que isso assume sentido positivo na vivência da paternidade na meia-idade. Ainda em relação à masculinidade e à imagem socialmente atribuída ao homem, estão presentes menções ao sair de casa, frequentar festas, conhecer pessoas e aproveitar a vida como eventos datados e associados ao homem jovem, como se tais aspectos não estivessem presentes nas mulheres, por exemplo, o que reforça o estereótipo do homem como alguém que amadurece mais lentamente do que a mulher e que pensa de modo mais egoísta em relação a se doar a uma outra pessoa, como no caso do nascimento de um filho (Silva, 2006).

Em relação aos aspectos considerados negativos do tornar-se pai na meia-idade Adriano e Marcelo apontaram a falta de aptidão física para realizar determinadas atividades que desempenhavam quando mais jovens e que gostariam de realizar com os filhos:

"A única coisa assim, que me deixa triste é que assim que com essa idade eu já parei de jogar, nossa como eu era bom, mas parei de praticar alguns esportes e não ter o filho pra ver que a gente já fez aquilo, a boa forma, né." (Adriano, 44 anos) 
"Quando eu era mais novo eu queria ter filho novo, pra ter essa aptidão física pra ficar com ele, porque ele chama eu pra brincar de bola e eu não gosto, não tenho aptidão mais pra correr tanto. Na piscina ele quer entrar todo dia, mas eu fui ficando velho e num gosto mais de água fria, né." (Marcelo, 48 anos)

Observou-se que Adriano e Marcelo relataram de habilidades e gostos que se perderam ou se modificaram com o passar dos anos. Em sua fala, Adriano pareceu reviver os momentos em que tinha por volta de 30 anos e jogava futebol, segundo ele, muito bem, revelando o desejo de que o filho presenciasse sua habilidade e disposição, o que reforça o desejo de que o filho o visse como ser potente, disposto e dotado de competência atlética. Além da percepção dessa falta de aptidão física, Marcelo relatou também uma indisposição para momentos como a água fria da piscina. De acordo com Ribeiro (2005), é característico dessa fase do ciclo vital as diversas alterações físicas, em que não só se constata uma diminuição da resistência e da energia física, como se verificam mudanças menos evidentes, como é o caso da redução na secreção da hormona testicular. Dessa forma, os relatos de Adriano e Marcelo referemse a percepções reais das mudanças corporais ocorridas ao longo dos anos, mas que parecem se tornar ainda mais evidentes na relação com o filho e nos momentos em que eles são solicitados para realizar determinadas atividades com estes. É nesses momentos que parece necessário valorizar os aspectos positivos da vivência paterna na meia-idade e buscar elementos para compensar os aspectos negativos: "agora é preciso tirar algo de bom né, num tenho mais aquele pique pra correr, mas no videogame ai num tem boca não" (Marcelo, 48 anos).

Joel e Antônio revelaram, respectivamente, como aspecto negativo dessa vivência, o receio de não presenciar o desenvolvimento dos netos e filha:

"Também tem um problema de casar mais velho, né, porque você vai viver seus filhos, mas não vai viver seus netos, eu sinto isso. Nem sei se vou conhecer meus netos, mas é um fato triste." (Joel, 57 anos)

"É estranho, porque nós dois (ele e a esposa) temos quase a mesma idade, então somos pais mais maduros e agora eu fico pensando que se ela se for (devido ao câncer), minha filha vai fica sem mãe e com um pai velho..." (Antônio, 58 anos)

Apesar do receio de morrer de Antônio estar associado ao diagnóstico de câncer de sua companheira, observou-se que esta questão não trouxe à tona apenas o medo dele e de sua filha de perdê-la, mas também a percepção da possibilidade de não acompanhar, da maneira desejada, o desenvolvimento de sua filha. Ambos, Antônio e Joel, parecem partir da compreensão ensinada pela biologia, em que na sequência natural dos fatos os mais velhos morrem primeiro (Alarcão, Carvalho, \& Pelloso, 2008; Bittencourt, Quintana, \& Velho, 2011). No entanto, essa vivência parece ficar ainda mais forte e dolorosa quando os participantes refletem acerca da idade dos seus filhos.

A este respeito, podemos acrescentar as contribuições de Kovács (2010), em que se considera que o adulto pode passar por crises como a chamada "crise da meia-idade", caracterizada por um período em que o mesmo vai se conscientizando de que é inevitável morrer, à medida que reconhece novas limitações físicas e vivencia importantes mudanças nos principais papéis desempenhados até então.

Ainda em termos de crises que atravessam cada estágio do desenvolvimento, a meia-idade é concebida por Erikson (1976) como um momento de reflexão e de revisão de vida. Na vertente positiva desta crise, o sentimento de possuir um conhecimento que pode contribuir com as gerações futuras é desvelado. Desta forma, o ser humano preocupa-se e dedica-se ao cuidado daquilo que gerou, o que é visível na transmissão de valores de pai pra filho. Em sua vertente negativa há uma centralização nos interesses pessoais, o que acaba levando a estagnação. Este mesmo autor associa a resolução satisfatória das crises presentes em cada estágio com a maturação e desenvolvimento saudável do ego, o que significa que tais situações podem desempenhar um papel importante no sentido de promover adaptações e aprendizados. Ser pai necessariamente envolveria a permanência do genitor ao longo de todo o ciclo vital do filho? Quais sentidos de ser pai podem emergir a partir das crises observadas nessa fase?

Observa-se que, nos relatos dos participantes, as características e mudanças ocorridas ao longo da vida e nesta fase do ciclo vital, sejam elas tomadas como positivas ou negativas, parecem vir à tona não só com suas percepções do próprio corpo e de seus sentimentos, mas também no exercício da função paterna e das exigências que esse papel apresenta.

\section{Repercussões da paternidade na conjugalidade e nas relações sociais e familiares}

Este eixo abarca as menções dos participantes às repercussões da paternidade em suas diversas relações, notadamente na conjugalidade e nas relações sociais e familiares. De acordo com Freitas et al. (2007), o curso da gravidez e o nascimento do filho podem 
gerar diferentes sentimentos vividos pelos casais, como tristeza, satisfação e insatisfação. Assim, para alguns casais esse momento traz alegrias e o desejo de conviver harmoniosamente, enquanto que, para outros, conflitos relacionados com o modo que cada um compreende e desempenha seus atributos sociais podem se acentuar. Ao falar de sua relação com a esposa Adriano se emocionou, dizendo que se lembrava de quando algumas pessoas lhe disseram que tudo ficaria mais difícil no casamento, mas que, no seu caso, o nascimento do bebê fez com eles ficassem mais unidos, afirmando ser difícil explicar esse sentimento de harmonia e carinho:

"A gente ficou mais unido, mais apegado um com o outro, até mais carinhoso. Nossa! (se emociona), é parte de dois, juntos, é incrível esta união, num dá para explicar. Muitos casais falam que quando a esposa engravida fica um relacionamento mais morno, né, mas é conoscofoi o contrário, nós ficamos mais unidos, mais carinhosos. "(Adriano, 44 anos)

É possível observar que assim como encontrado no estudo de Gonçalves et al. (2013), a chegada do filho melhorou aspectos da relação conjugal de Adriano, trazendo além de uma maior satisfação e carinho pela esposa, a sensação de uma completude do casal. Diferente de Adriano, Marcelo relatou acerca de um distanciamento com a esposa que teve início na gravidez e se mantém até os dias atuais:

"Mudou sim. Mudou pelo seguinte, a gente pode até falar em intimidade. Eu dormi na cama com ela e tive relação com ela até seis meses, quando a barriga começou a aparecer. Ai quando começou a aparecer a gente não dormiu mais junto. Então a gente se afastou demais, e por causa disso, hoje ela dorme com ele até hoje e eu no outro quarto." (Marcelo, 48 anos)

Freitas et al. (2007) compreendem que, para muitos homens, a assunção do sentimento paterno é um fato que só ocorre após o nascimento, sendo que, em alguns casos, mesmo após a chegada do filho, este sentimento ainda não é tão perceptível. Dessa forma, assim como ocorrido com Marcelo, no experienciar da paternidade, poderá ocorrer o distanciamento de muitos homens do processo da gravidez, com possibilidade de se manter após o nascimento, o que se relaciona com a ambivalência presente nesse período. Ainda em termos das repercussões na relação conjugal, Adriano e Antônio relataram acerca da redução do tempo a dois após o nascimento do filho, destacando a importância do casal se organizar em relação ao papel paterno e materno e também aos momentos que devem ser apenas dos dois:

"Criança ocupa muito tempo, a gente acaba dando mais atenção pra ele, tanto eu quanto ela, mas a gente continua mais apegado, tem os momento dos três e o nosso também, tem que saber organizar." (Adriano, 44 anos).

O tempo sozinhos diminuiu, mas a cumplicidade aumentou e isso compensa as mudanças, é preciso entender." (Antônio, 58 anos)

Os achados dos estudos realizados por Jager e Bottoli (2011) e Gonçalves et al. (2013) corroboram as questões levantadas por Adriano e Antônio acerca da necessidade de se organizar enquanto casal após a chegada do filho. No estudo realizado por Gonçalves e colaboradores com 38 pais primíparos acerca da experiência da paternidade aos três meses do bebê, seis participantes da amostra explicitaram que a chegada do filho havia diminuído a liberdade e o tempo para a relação conjugal, já que as atenções se voltavam para o bebê. Observou-se, dessa forma, a tentativa de Adriano e Antônio em realizar adaptações na vida conjugal após a chegada do filho, de modo que essas não reduzam a qualidade da relação com a esposa. Já no relato de Marcelo, destacou-se uma dificuldade do casal em organizar as funções parentais e a relação conjugal, que teve início na gravidez e vem perdurando nessa relação após cinco anos do nascimento do filho.

Adriano e Antônio destacaram que essa redução de tempo também se estendeu para as relações sociais, apontando uma diminuição nas atividades de lazer com os amigos e um afastamento dos mesmos. A distinção entre eles é que, apesar de ambos não relatarem essa questão com um tom negativo, Adriano a evidenciou como algo que percebe como natural em todos os casais que têm filhos, enquanto que Antônio falou de um afastamento que se deu de sua parte, devido às brincadeiras de seus amigos em relação à sua idade.

"Eu acredito assim que muda pra todo casal, porque por ter um filho, a gente acaba dando muita atenção pro filho e às vezes deixa a desejar muito com os amigos, deixa de sair, mas a gente tenta não prejudicar a amizade, a relação com os familiares. Acho que a família e os amigos às vezes reclamam, mas depois vão entendendo que não é porque a gente quer, é porque tem coisas que num dá pra fazer mesmo, lugar que num dá pra ir com bebê. (Adriano, 44 anos). 
"Afastei um pouco.... Eles falavam né, até que enfim, já tava mais pra vovó do que pra titio e agora pai, eu num ligava, porque ninguém melhor que eu sabia minha idade, mas isso num é coisa que se faz." (Antônio, 58 anos)

No que diz respeito às relações familiares, Joel e Antônio destacaram uma melhora na qualidade da relação com a família, apontando uma maior aproximação após o nascimento do(s) filho(s). Joel relatou acerca de uma proximidade da família que não diz respeito apenas aos filhos, mas sim em relação a ele, uma vez que acreditava que a família o percebia como alguém que não se tornaria pai e ficaria sozinho, o que é relatado como uma percepção negativa da família em relação a ele. Antônio, por sua vez, relatou de uma proximidade desejada e sonhada por ele enquanto membro da família, que se tornou realidade apenas após o nascimento de sua filha.

Esses achados acerca das repercussões da paternidade nos relacionamentos interpessoais também se destacaram nos discursos da amostra do estudo de Gonçalves et al. (2013), em que a maioria dos pais entrevistados mencionou mudanças relativas ao nascimento do filho, seja em sua rotina, na relação com outros familiares e com a esposa, em seus planos para o futuro ou em aspectos subjetivos. Quanto à rotina, doze de 38 pais especificaram a adaptação em horários das atividades em casa e no trabalho, além da diminuição da frequência de atividades de lazer como passeios, viagens e festas. No entanto, assim como no presente estudo, essas mudanças não foram relatadas como algo negativo ou difícil.

Torna-se importante refletir que ao considerarmos a literatura científica acerca de homens e casais de meiaidade é possível perceber o quanto a vivência paterna nessa fase desafia o que é esperado e colocado como característica desse período do ciclo vital. Destaca-se que os estudos acerca dos homens de meia-idade focam principalmente em uma diminuição do desempenho sexual e a perda de poder, enquanto que, os poucos estudos acerca casais de meia-idade, o que é o caso de Antônio e Marcelo, caracterizam essa fase como aquela em que se verifica o maior número de saídas dos filhos e de entradas noras e/ou genros e netos no sistema familiar. Assim, foca-se na necessidade do casal reestruturar a sua relação após a saída dos filhos (Ribeiro, 2005), movimento inverso ao vivenciado pelos participantes do nosso estudo, em que se vê a necessidade de se adaptar em relação ao nascimento do filho e também às transformações referentes a esta fase do ciclo de vida, que parecem se tornar ainda mais evidentes quando esses são convidados a desem- penhar e refletir acerca de algumas atividades com seus filhos.

A meia-idade, desse modo, oferece a esses pais não a crise por ver seus filhos saindo de casa, mas por acompanhar o nascimento e crescimento dos mesmos, o que nos permite afirmar que cada fase do ciclo vital poderá trazer eventos e desafios diversos a depender do contexto e dos percursos individuais que se sobrepõem ao critério idade, o que nos obriga a compreender o desenvolvimento para além de uma perspectiva exclusivamente focada na faixa etária e sim em aspectos mais culturais. Esse movimento promove a necessidade de analisar de que modo as pessoas se comportam e se transformam ao longo do tempo e a própria assunção dos diversos modos de ser família, apresentando, por este estudo, a paternidade contemporânea como fenômeno ainda recente na literatura científica.

\section{CONSIDERAÇÕES FINAIS}

A partir dos resultados do presente estudo, observou-se que a vivência paterna na meia-idade é composta por múltiplas articulações, construída a partir das referências das quais os participantes são herdeiros e aberta a (re)criações. Assim, destacou-se nos discursos a influência do modelo de paternidade exercido pelo próprio genitor na construção do modo de ser pai dos participantes, em que se pode observar dois movimentos: a busca pela ruptura com os aspectos negativos da experiência com o próprio pai e a busca da permanência de aspectos positivos daquela experiência, o que na perspectiva psicanalítica de Benghozi (2010) possibilita a remalhagem dos vínculos. A partir dessa compreensão, as vivências em relação ao genitor na assunção da paternidade foram colocadas em evidência, mas não como determinantes desse processo, uma vez que observou-se que os desafios e características da meia-idade e o porvir das relações sociais, familiares e conjugais nesta fase surgiram como aspectos significativos para a construção da paternidade. A conjugalidade, evocada pelos participantes, também pode possibilitar a remalhagem dos vínculos estabelecidos nas primeiras relações, de modo que o exercício da paternidade pode ser auxiliado pela parceria com a esposa e com os aspectos positivos desse relacionamento amoroso. No entanto, em apenas um casal esse aspecto conjugal foi mencionado como significativo, o que pode sugerir a necessidade de que esses pais relatem a sua própria experiência como genitores, priorizando o relacionamento com os filhos ao falar do que compreendem por paternidade. 
Dentre as especificidades da experiência da paternidade na meia-idade emergiram aspectos considerados positivos e negativos que parecem se referir a percepções e mudanças reais em relação à fase do ciclo vital que se encontram, mas que tomam novo sentido ao atrelar-se com as demandas da paternidade. Os desafios da idade aparecem associados à necessidade de se mostrarem potentes, másculos e saudáveis para acompanhar o desenvolvimento dos filhos, o que também envolve a consideração de que há limitações físicas que, no entanto, não dificultam uma boa vinculação com os filhos e boa experiência como pais.

Considerando a grande importância de se investigar os diversos envolvidos na transição para a parentalidade, espera-se que este estudo possa fomentar novas investigações acerca da vivência concreta da paternidade e dos sentidos que podem ser atribuídos a ela em diferentes etapas do ciclo de vida a partir do relato dos seus próprios protagonistas. Destaca-se que a paternidade não possui um sentido unívoco, não podendo ser balizada em termos de características. Assim, o ciclo de vida nos ajuda a pensar em possibilidades e limitações para essa experiência, embora devamos reconhecer que a qualidade do vínculo estabelecido extrapole os aspectos etários e refira-se, de modo bastante particular, às experiências emocionais construídas em toda a vida, quer seja com o próprio pai, com a esposa ou com a rede de apoio mais próxima. O pai contemporâneo, aqui retratado, confere maior visibilidade a essa população que possui especificidades, desafios e potencialidades intimamente relacionadas ao ser homem na meiaidade, o que nos ajuda a compreender a multiplicidade de arranjos e experiências que atravessam e constituem a paternidade.

\section{REFERÊNCIAS}

Alarcão, A. C. J., Carvalho, M. D. de B., \& Pelloso, F. M. (2008). A morte de um filho jovem em circunstância violenta: compreendendo a vivência da mãe. Revista Latino-Americana de Enfermagem, 16(3), 341-347.

Bittencourt, A. L. P., Quintana, A. M., \& Velho, M. T. A. C. (2011). A perda do filho: Luto e doação de órgãos. Estudos de Psicologia, 28(4), 435-442. http://dx.doi.org/10.1590/S0103-166X2011000400004

Balancho, L. S. F. (2004). Ser pai: Transformações intergeracionais na paternidade. Análise Psicológica, 22(2), 377-386.

Benghozi, P. (2010). Malhagem, filiação e afiliação - Psicanálise dos vínculos: Casal, família, grupo, instituição e campo social. (E. D. Galery, Trad.). São Paulo: Vetor.

Cecílio, M. S. \& Scorsolini-Comin, F. (2013). Relações entre conjugalidade e parentalidades adotiva e biológica. Psico (Porto Alegre), 44(2), 245-256.

Costa, N. R. A. \& Rossetti-Ferreira, M. C. (2009a). Acolhimento familiar: Uma alternativa de proteção para crianças e adolescentes. Psicologia: Reflexão e Crítica, 22(1), 111-118. http://dx.doi.org/10.1590/S0102-79722009000100015

Costa, N. R. A. \& Rossetti-Ferreira, M. C. (2009b). Become mother and father in late adoption: A case study. Child and Family Social Work, 14, 58-67. http://dx.doi.org/10.1111/j.1365-2206.2008.00581.x

Cúnico, S. D. \& Arpini, D. M. (2013). A família em mudanças: Desafios para a paternidade contemporânea. Pensando Familia, 17(1), 28-40.

Erikson, E. H. (1976). Identidade: juventude e crise. Rio de Janeiro: Zahar.

Ferreira, M. E. M. (2008). A meia-idade e a alta modernidade. Construção Psicopedagógica, 16(13), 77-91

Freitas, W. M. F, Coelho, E. A. C., \& Silva, A. T. M. C. (2007). Sentir-se pai: A vivência masculina sob o olhar de gênero. Caderno de Saúde Pública, 23(1), 137-45. http://dx.doi.org/10.1590/S0102-311X2007000100015

Freitas, W. M. F., Silva, A. T. M. C., Coelho, E. A. C., Guedes, R. N., Lucena, K. D. T., \& Costa, A. P. T. (2009). Paternidade: Homem no papel social de provedor. Revista de Saúde Pública, 43(1), 85-90. http://dx.doi.org/10.1590/ S0034-89102009000100011

Gabriel, M. R. \& Dias, A. C. (2011). Percepções sobre a paternidade: descrevendo a si mesmo e o próprio pai como pai. Estudos de Psicologia, 16(3), 253-261. http://dx.doi.org/10.1590/S1413-294X2011000300007

Gomes, A. J. S. \& Resende, V. R. (2004). O pai presente: O desvelar da paternidade em uma família contemporânea. Psicologia: Teoria e Pesquisa, 20(20), 119-125. http://dx.doi.org/10.1590/s0102-37722004000200004

Gonçalves, T. R., Guimarães, L. E., Silva, M. R., Lopes, R. C. S., \& Piccinini, C. A. (2013). Experiência da paternidade aos três meses do bebê. Psicologia: Reflexão e Crítica, 26(3), 599-608. http://dx.doi.org/10.1590/s010279722013000300020

Hennigen, I. (2010). Especialistas advertem: O pai é importante para o desenvolvimento infantil. Fractal: Revista de Psicologia, 22(1), 169-184. http://dx.doi.org/10.1590/s1984-02922010000100013

Jager, M. E. \& Bottoli, C. (2011). Paternidade: vivência do primeiro filho e mudanças familiares. Psicologia: Teoria e Prática, 13(1), 141-153. 
Kovács, M. J. (2010). Morte e desenvolvimento humano (5ª ed.). São Paulo: Casa do Psicólogo.

Lamb, M. E. (2000). Fathering. In Encyclopedia of Psychology (Vol. 3, pp. 338-341). Oxford: American Psychological Association. http://dx.doi.org/10.1037/10518-144

Levandowski, D. C. (2001). Paternidade na adolescência: Uma breve revisão da literatura internacional. Estudos de Psicologia, 6(2), 195-209. http://dx.doi.org/10.1590/s1413-294x2001000200007

Levandowski, D. C. \& Piccinini, C. A. (2002). A interação pai-bebê entre pais adolescentes e adultos. Psicologia: Reflexão e Crítica, 15(2), 413-424. http://dx.doi.org/10.1590/s0102-79722002000200018

Levandowski, D. C. \& Piccinini, C. A. (2006). Expectativas e sentimentos em relação à paternidade entre adolescentes e adultos. Psicologia: Teoria e Pesquisa, 22(1), 17-28. http://dx.doi.org/10.1590/s0102-37722006000100003

Leão, M. A. B. G. \& Gíglio, J. S. (2002). Psicodinâmica da mulher trabalhadora de meia-idade em fase de préaposentadoria. Psico-USF, 7(2), 185-194.

Meihy, J. C. S. B. \& Holanda, F. (2010). História oral: Como fazer, como pensar. São Paulo: Contexto

Orlandi, R. \& Toneli, M. J. F. (2005). Sobre o processo de constituição do sujeito face à paternidade na adolescência. Psicologia em Revista, 11(18), 257-267.

Ribeiro, M. T. M. L. S. R. (2005). Casais de meia-idade: Estudos com casais portugueses numa perspectiva sistêmica. Psicologia, 19(1-2), 57-85.

Rossetti-Ferreira, M. C., \& Costa, N. R. A. (2012). Construcción de vínculos afectivos en contextos adversos de desarrollo: Importancia y polemicas. Scripta Nova (Barcelona), 26(325), 98-13.

Sampaio, K. J. A. J., Villela, W. V., \& Oliveira, E. M. (2014) Significados atribuídos a paternidade por adolescentes. Acta Paulista de Enfermagem, 27(1), 1-5. http://dx.doi.org/10.1590/1982-0194201400002

Shwalb, D. W. \& Shwalb, B. J. (2014). Fatherhood in Brazil, Bangladesh, Russia, Japan, and Australia. Online Readings in Psychology and Culture, 6(3). http://dx.doi.org/10.9707/2307-0919.1125

Silva, S. G. (2006). A crise da masculinidade: Uma crítica à identidade de gênero e à literatura masculinista. Psicologia: Ciência e Profissão, 26(1), 118-131. http://dx.doi.org/10.1590/s1414-98932006000100011

Staudt, A. C. P. \& Wagner, A. (2008). Paternidade em tempos de mudança. Psicologia: Teoria e Prática, 10(1), 174-185.

Trindade, E. \& Bruns, M. A. T. (2004). Ser homem na meia-idade: Vivências e perspectivas. In D. S. P. Castro, J. D. Piccino, R. S. Josgrilberg, \& T. A. Goto (Orgs.), Corpo e existência (pp. 225-232). São Bernardo do Campo, SP: Editora da Universidade Metodista de São Paulo.

Trindade, E. \& Bruns, M. A. T. (2007). Meia-idade masculina: Significados do envelhecimento. In M. A. T. Bruns, \& M. C. S. Del-Masso (Orgs.), Envelhecimento humano: Diferentes perspectivas (pp. 35-52). Campinas, SP: Átomo e Alínea.

Trindade, Z. A. \& Menandro, M. C. S. (2002). Pais adolescentes: Vivência e significação. Estudos de Psicologia, 7(1), 15-23. http://dx.doi.org/10.1590/s1413-294x2002000100003

Vieira, E. N. \& Souza, L. (2010). Guarda paterna e representações sociais de paternidade e maternidade. Análise Psicológica, 28(4), 581-596

\footnotetext{
Autores: Universidade Federal do Triângulo Mineiro.

\section{Endereço para correspondência:}

Fabio Scorsolini-Comin

Programa de Pós-Graduação em Psicologia

Universidade Federal do Triângulo Mineiro

Av. Getúlio Guaritá, 159, 3ํandar - Abadia

CEP 38025-440 Uberaba, MG, Brasil
}

MAYARA COLLETI - Psicóloga pela Universidade Federal do Triângulo Mineiro e mestranda em Psicologia pela Universidade de São Paulo. FABIO SCORSOLINI-COMIN - Doutor em Psicologia pela Universidade de São Paulo e docente do Programa de Pós-Graduação em Psicologia da

Recebido em: 12.11 .14

Aceito em: 14.05 .15 